\title{
ИСПОЛЬЗОВАНИЕ МАЛОУГЛОВОГО ИЗМЕРИТЕЛЯ ДИСПЕРСНОСТИ В АВТОМАТИЗИРОВАННЫХ СИСТЕМАХ НЕПРЕРЫВНОГО МОНИТОРИНГА ГРАНУЛОМЕТРИЧЕСКОГО СОСТАВА АЭРОЗОЛЕЙ
}

\author{
Н.Н. Дьяков ${ }^{1}$, Ю.А. Мальченко ${ }^{1}$, С.А. Боброва ${ }^{1}$, \\ А.И. Рябинин ${ }^{1}$, А.Е. Липченко ${ }^{1}$, В.В. Таранов ${ }^{2}$
}

${ }^{1}$ Севастопольское отделение Государственного океанографического института им. Н.Н. Зубова, РФ, г. Севастополь, ул. Советская, 61

E-mail:sogoin@mail.ru

${ }^{2}$ Институт коллоидной химии и химии воды им. А.В. Думанского НАН Украины, Украина, Киев-142, просп. Акад. Вернадского, 42

E-mail:lambit@ukr.net

Приведены результаты наблюдений за гранулометрическим составом аэрозолей на стационарном посту в г. Севастополе в 2015-2016 гг. Показаны основные закономерности распределения аэрозолей в отдельных размерных группах и их связь с параметрами окружающей среды. Отмечена актуальность предлагаемого мониторинга различных показателей аэрозоля.

Ключевые слова: аэрозоли, гранулометрический состав, дифракция лазерного излучения, метеорологические факторы.

Введение. Являясь сложной гетерогенной системой, определяющей не только качество и комфортность жизни, но и само ее существование, атмосферный воздух нуждается в непрерывном мониторинге по большому количеству показателей. Однако наращивание количества определяемых показателей не может служить примером продуктивного подхода к мониторингу качества воздушной среды [1-10]. Действительно, наблюдающаяся в последнее время тенденция к увеличению количества такого опасного явления, как образование смога в крупных городах связана с действием большого количества техногенных факторов и их наложения на природные процессы. В этой связи представляется важным выделение одного или нескольких процессов, определяющих комплексное воздействие факторов на состояние воздушной среды и ухудшение ее показателей. К таким факторам могут быть отнесены величины концентрации аэрозолей в различных размерных группах, анализ распределения в которых (в сочетании со статистическими характеристиками метеорологических факторов) позволяет выявить основные причины образования смога, его отделение от природных явлений и, как следствие, выявить опасность явления в целом.
В настоящее время разработано большое количество приборов, позволяющих вести непрерывное измерение гранулометрического состава аэрозолей в самом широком диапазоне размерностей: от наночастиц размером менее 0,1 мкм, до структур размером более 100 мкм. Практически все современные приборы используют сходные принципы действия, основанные на измерении величин абсорбции и анализа дифракционной картины рассеяния монохромного излучения на поверхности аэрозольных частиц [9-12]. В отличие от использовавшихся ранее методов измерения показателей, основанных на механическом отделении частиц аэрозолей с использованием методов фильтрации через ультрапористые материалы или осаждение в коронном разряде, с последующим гравиметрическим измерением содержания взвешенных частиц, современные методы являются неразрушающими по отношению к анализируемой среде и могут быть использованы в последовательном включении в цепь независимых анализаторов параметров, что, несомненно, повышает информативность измерений.

Описанные недостатки измерителей содержания аэрозолей во многом определили и существовавшие подходы к нормированию показателей по ПДК и их 
дальнейшую эволюцию. Так, существовавшие в 70-е и начале 80 -х годов прошлого столетия нормативы содержали требования к осуществлению контроля за валовыми показателями содержания аэрозолей. В дальнейшем, появление новых методов определения показателя, позволяющего проводить количественные измерения содержания частиц в различных размерных группах, привел к «упразднению» нормирования валового содержания аэрозолей в пользу отдельных групп [13-17]. В настоящее время нормируется величина массовой концентращии аэрозолей в размерных группах до 2,5 и до 10 мкм (величины PM2,5 и PM10 соответственно), а также ведутся работы по введению нормативов загрязнения воздуха частицами в диапазоне менее 1 мкм (PM1,0).

Существуюшие в настоящее время критерии оценки токсичности воздуха по содержанию в нем аэрозольных частиц базируются на величинах массовой концентрации, которая, в отличие от счетной, не может быть измерена на основании анализа картины дифракции лазерного излучения. Это привносит в получаемые оценки некоторую долю произвольности и заставляет проводить исследования в направлении повышения точности измерений путем внесения соответствующих коэффициентов и поправок. Также, не вполне объективная оцен- ка показателей гранулометрического состава аэрозолей получается и по величинам объемной концентрации. Все расчеты, используемые для перевода величины счетной концентрации в объемную, основаны на априорной гипотезе о сферической форме частиц аэрозоля, что, по вполне понятным причинам, далеко не всегда соответствует действительности $[4,6,7]$. Это, а также отсутствие данных о плотности отдельных частиц и всей массы аэрозолей, вносит известную неопределенность в получаемые данные и заставляет проводить поиск независимых критериев оценки качества воздуха не отягощенные данной проблематикой, что также является одним из направлений работ, описанных в статье.

Материалы и методы. В качестве базового оборудования для выполнения мониторинга был использован программно-anпаратный комплекс ИдЛ-1М, разработанный Институтом коллоидной химии и химии воды (ИКХХВ) и Государственным океанографическим институтом (ГОИН). Изначально комплекс предназначался для поиска и измерения количества кластерных структур в воде. Комплекс был модернизирован введением проточной кюветы с кварцевыми окнами для осуществления непрерывной прокачки воздуха. Также было модернизировано программное обеспечение введением в него соответствующих опщий.

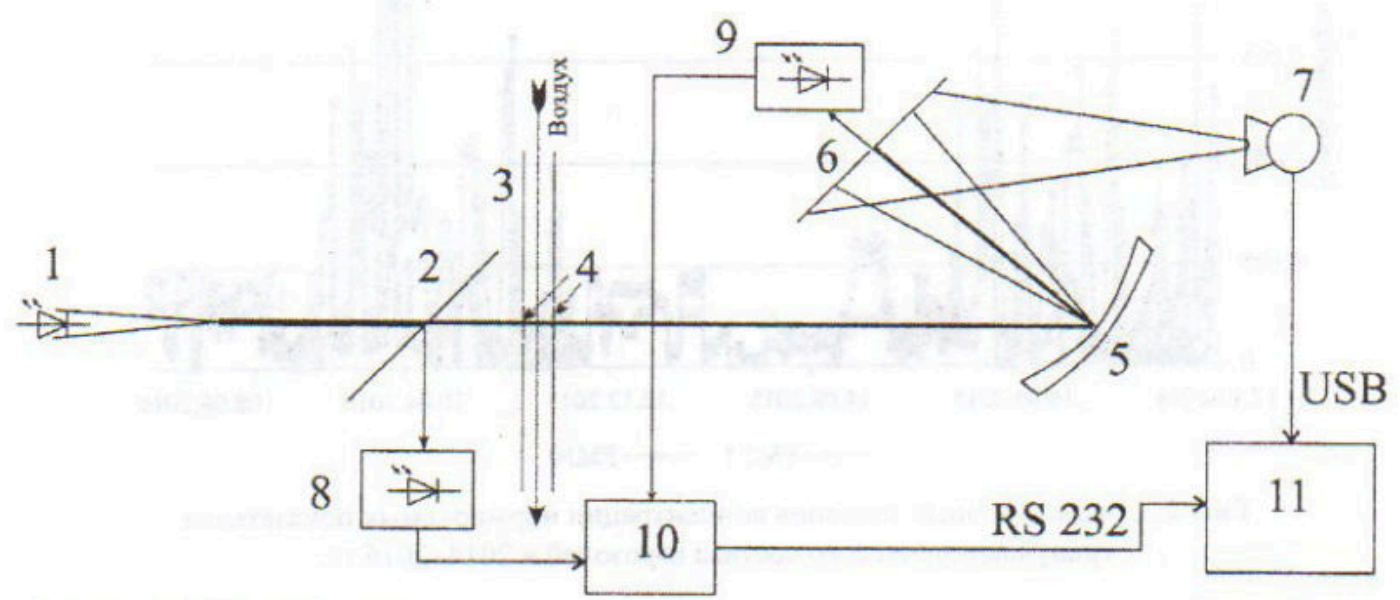

Рис. 1. Оптическая и принципиальная схема лазерного измерителя дисперсности ИдЛ-1М

Принципиальная схема прибора показана на рис. $1[18,19,22,23]$. Воздух прокачивается через проточную кювету 3 и проходит мимо кварцевых окошек 4 . Источником монохроматичного излуче- ния служит лазерный светодиод 1 . Часть светового потока отражается полупрозрачным зеркалом и направляется на фотодиод 8. Основной поток излучения проходит через кювету, где он частично 
поглощается аэрозолями, а частично рассеиваются, формируя характерную дифракционную картину. Отражаясь от зеркала 5, световой поток попадает на матовый экран с отверстием 6. Дифракционная картина на экране сканируется веб-камерой 7. Часть потока проходит через отверстие в экране на фотодиод 9. Разность значений отраженного и поглощенного светового потока анализируется микропроцессором 10 и по каналу RS232 передается на ПК 11. По каналу USB передается изображение с вебкамеры, выполняющей фиксацию статических изображений дифракционной картины с частотой 50 Гц. Время накопления информации задается опционально и составляло величину $180 \mathrm{c}$.

Выбранные условия позволили проводить непрерывное и круглосуточное измерение содержания аэрозолей в воздухе в автономном режиме. В выходньг данных была представлена информация об общей конщентрации аэрозолей в 16 размерных группах в диапазоне 1-12 мКМ в единицах счетной и объемной концентрации, а также процентное содержание аэрозолей определенных раз- мерных гругп относительно их валового содержания в заданном диапазоне. Одновременно с измерением гранулометрического состава при помощи автоматической метеостанции выполнялся сбор данных о метеопараметрах в момент измерений. В состав измеряемых параметров входили: температура, влажность, направление и скорость ветра, давление, общая освещенность и УФ-индекс, а также количество осадков в случае их выпадения.

Весь комплекс приборов был установлен на метеоплощадке здания СО ГОИН, расположенного в центре города. Общая высота точки размещения аппаратуры составила 100 м над уровнем моря, что позволило практически полностью исключить влияние местных источников генерации аэрозолей (транспорт, котельные и т.п.). Для выполнения измерений в полевых условиях использовался портативный счетчик аэрозолей SEM DT-9880. Предварительная обработка данных и формирование сводных таблиц, пригодных для дальнейшего анализа выполнялось с использованием пакета Origin Pro 9.0.

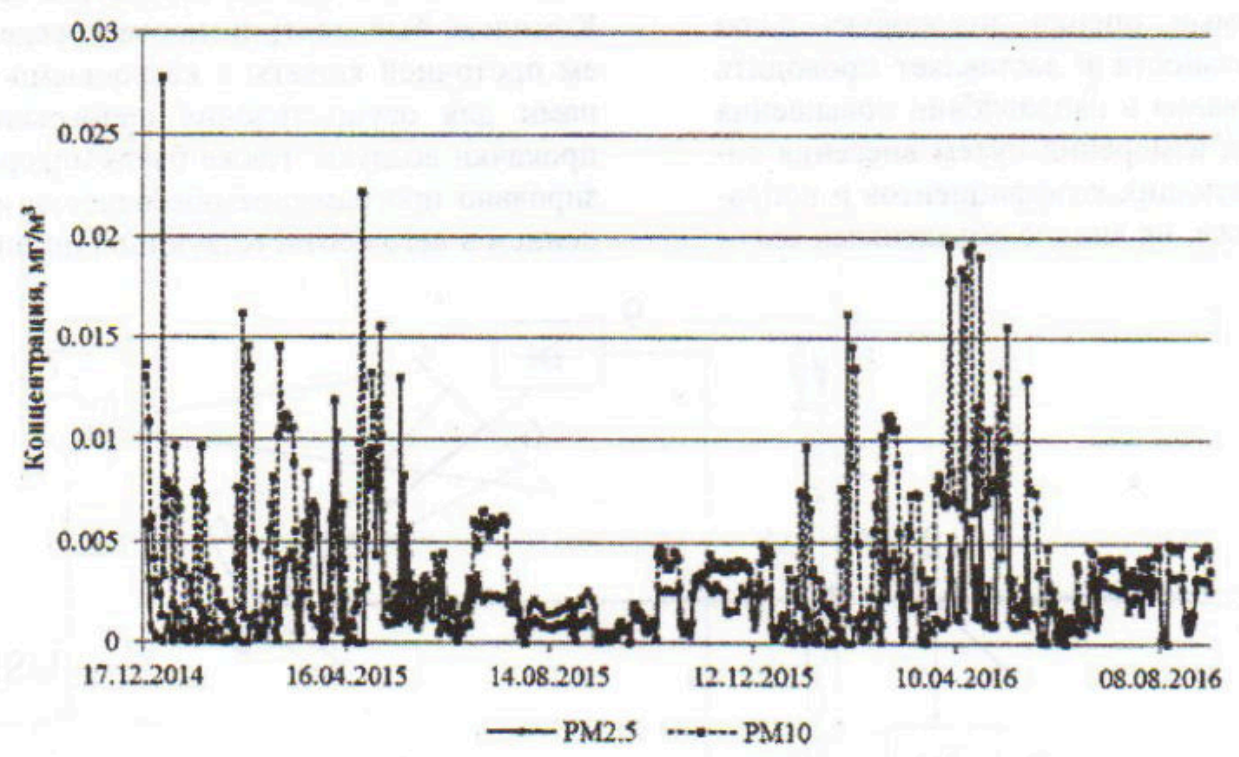

Рис. 2. Среднесуточные значения концентрации нормируемых показателей гранулометрического состава аэрозолей в 2014-2016 гr.

Полученные результаты. На рис. 2 представлены диаграммы среднесуточных величин нормируемых показателей РМ2,5 и РМ10. При ПДК для среднесуточных значений равных 0,035 и
$0,060 \mathrm{mr} / \mathrm{M}^{3}$ соответственно, ни в одной из серий измерений превышения нормируемых величин выявлено не было. Это свидетельствует о возможности использования данной точки в качестве опор- 
ной для выявления случаев дальнего и локального трансграничного переноса. В период проведения мониторинга в конце 2014-2016 гг. нами не было зафиксировано ни одного случая т.н. сверхдальнего переноса, что свидетельствует о невысокой частоте явления. Единственный случай, который однозначно может быть отнесен к этой категории, наблюдался нами в апреле 2013 г. и был описан в [3, 18]. Тогда, насыщение воздуха Севастополя аэрозолями различных размерных групп, было связано с выходом воздушньг масс, сформировавшихся над $\mathrm{Ce}$ верной Африкой через Балканский полуостров на Крым и далее на восток. В Севастополе это привело к насыщению воздуха пылью, имеющей характерную окраску и гранулометрический состав. Такие явления, естественно, не могут не иметь негативных последствий в ближайшей и долгосрочной перспективе. Поступление абразивных материалов, образовавшегося при эрозии верхнего слоя почвы, может служить одним из примеров негативного действия аэрозолей в техносфере. Совершенно очевидно, что, являясь компонентами с выявленным резорбтивным действием, поступление аэрозолей в организм не может не отразиться на здоровье населения.

Отмечается также высокая сезонная изменчивость показателей. Диаграммы имеют характерные лепестки, вытянутые в восточном и западном направлении. Такая особенность характерна для аэрозолей, имеющих источник генерации на поверхности Земли. Действительно, логично предположить, что для проникновения вглубь территории, аэрозоли, имеющие более высокую плотность, должны иметь меньшие размеры. Для морских аэрозолей, образующихся в результате «отрыва» капли при разрыве газового пузыря или отрыве фрагментов морской пены, характерны более высокие значения линейного размера [19-24]. Типичным размером частиц морского аэрозоля, генерируемого морской поверхностью при умеренных скоростях ветра являются величины близкие к 7 мкм [9, 22, 23]. Роза направлений для обоих параметров (рис. 3) имеет минимум при северном направлении ветра. Причина этого не вполне понятна и возможно связана с застройкой в северном направлении. Косвенно это подтверждается снижением средней скорости ветра.

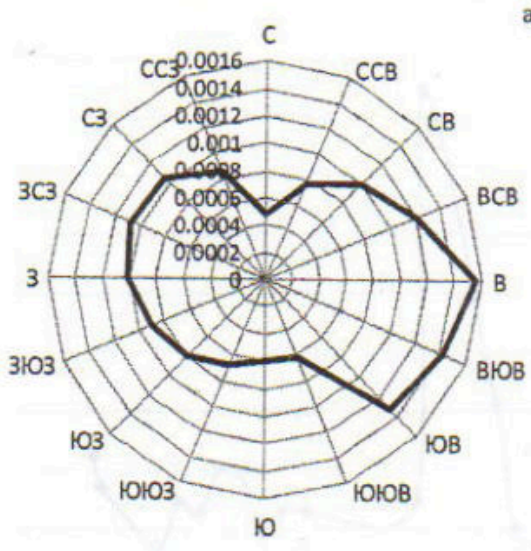

a)

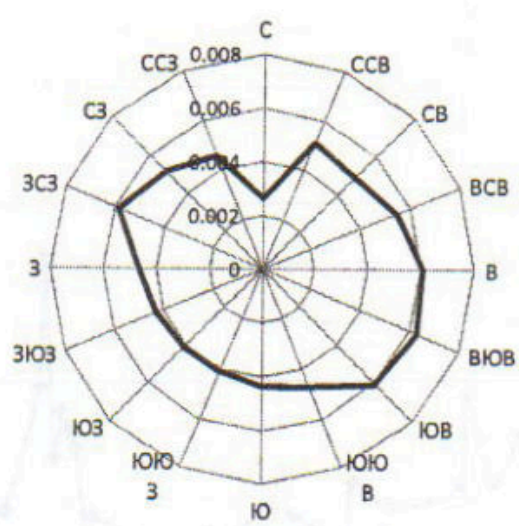

6)

Рис. 3. Средние значения концентрации показателей РМ2,5 (a) и PM10 (б) при различных направлениях ветра в 2014-2016 гг.

Влияние техногенного источника аэрозолей показано на рис. 4 , на котором представлено схематическое изображение вертикального профиля распределения нормируемых показателей PM2,5 и РМ10. Снятие профиля проводилось летом 2015 г. при равномерном движении по маршруту Малахов курган (высота около 100 м над уровнем моря) - пляж «Ушакова балка», расположенный на берегу Севастопольской бухты. Наблюдающиеся на диаграмме всплески пространственно привязаны к техногенным источникам аэрозолей. 


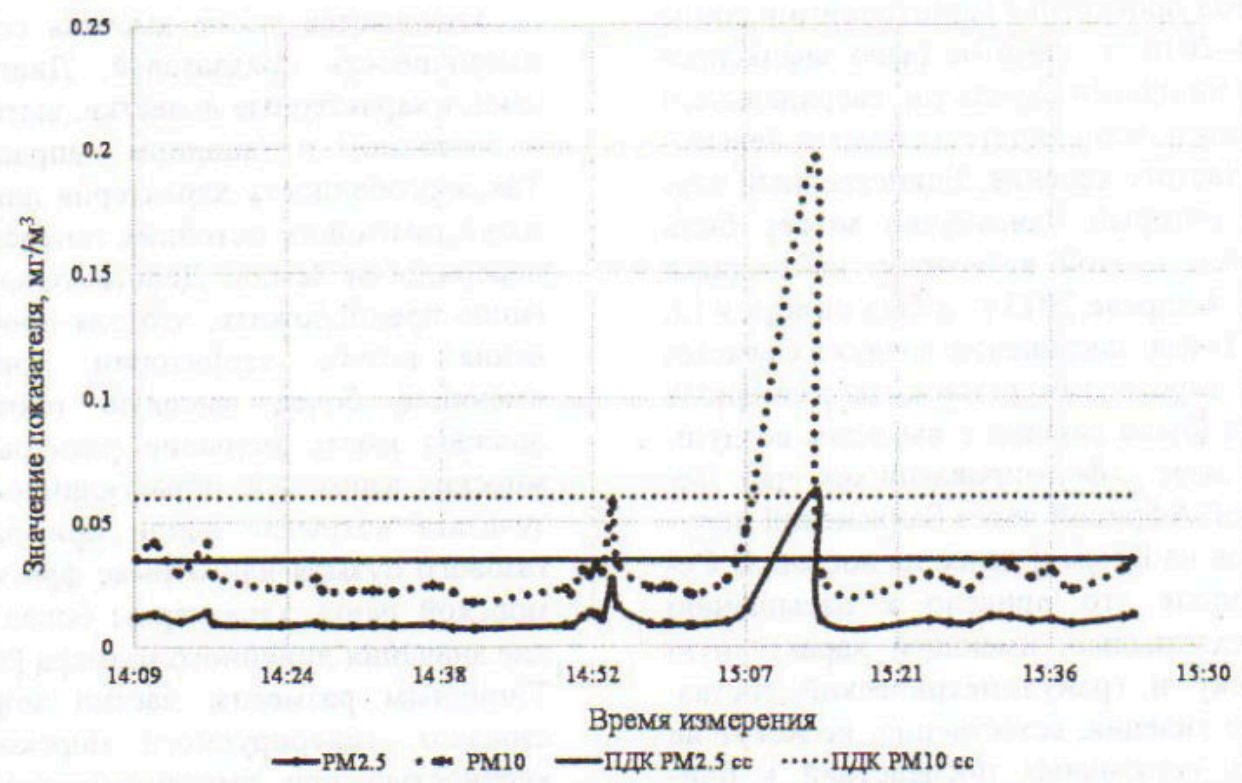

Рис. 4. Вертикальный профиль нормируемых значений показателей РМ2,5 и РМ10 на разрезе Малахов курган Ушакова балка 27.08.2015 и величины их ПДК

Первый всплеск в 14:55 ч был связан с несанкционированным сжиганием древесины, а второй, более сильный, - с пересечением автотрассы. Аналогичные выводы могут быть получены и на основании оценок, сделанных по интегральным величнам класса качества воздуха по ISO 14644-1-99 [25] (рис. 5). Все значения класса качества воздуха близки к безразмерной величине 7.0, которая может. быть в первом приближении принята за величину ПДК.

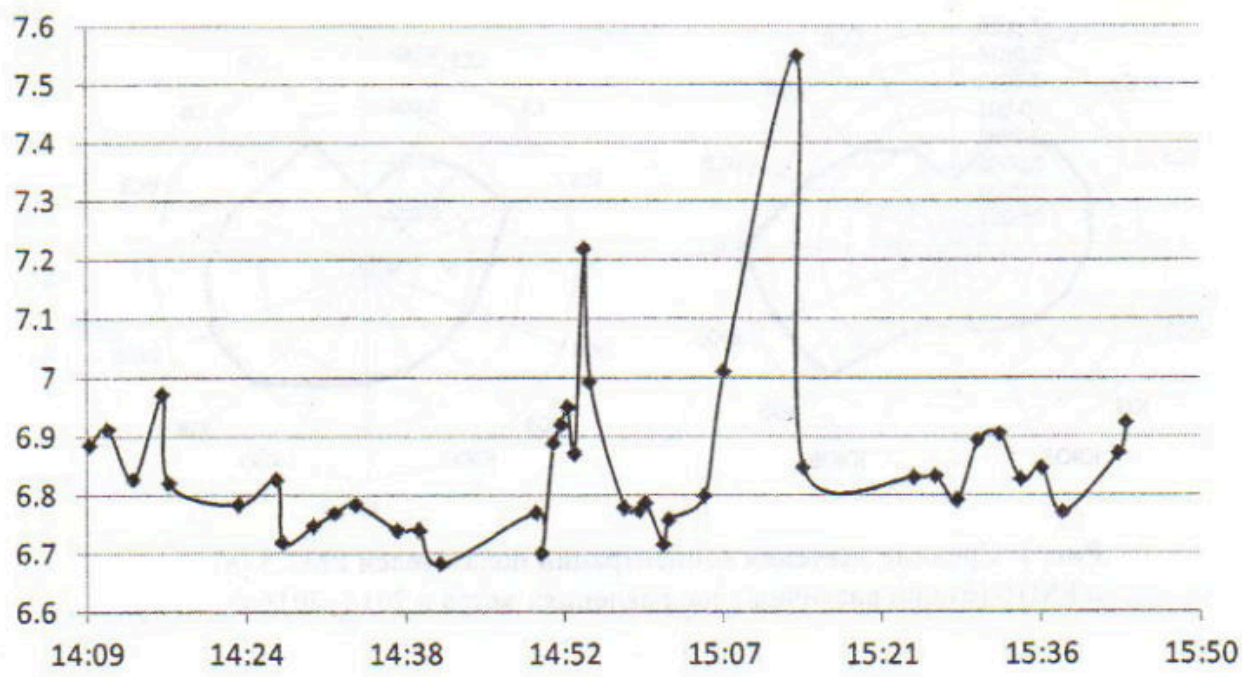

Рис. 5. Вертикальный профиль класса ISO 14644-1-99

на разрезе Малахов курган - Ушакова балка 27.08.2015

Заключение. Проведенные исследования показали актуальность мониторинга гранулометрического состава аэрозолей. Выявлены особенности се- зонной изменчивости гранулометрического состава аэрозолей, обусловленные в большей степени климатическими условиями. 
Формирование гранулометрического состава аэрозолей в воздухе г. Севастополя происходит при сильном влиянии основных источников аэрозолей: выветривания геологических пород и поступления сухих и влажных аэрозолей с поверхности моря. Разделение этих потоков принципиально возможно на основании данных о гранулометрическом составе. Наиболее вероятным источником мелкодисперсных аэрозолей являются пылевые частицы, а более крупных - морская поверхность.

Существующие методики нормирования воздействия аэрозолей на здоровье населения не вполне подходят для постановки на поточное определение, т.к. содержат неопределенные факторы такие, например, как плотность частиц аэрозолей. Кроме того, все методики измерения показателей исходят из допущения о сферической форме частиц, которое не может быть признано обоснованным с учетом особенностей формирования аэрозолей. Частично эта неопределенность может быть преодолена нормированием других показателей, таких как счетная и/или объемная концентрация. Эти предложения требуют дальнейшей проработки, и исследования в данном направлении будут продолжены.

Работа выполнена при финансовой поддержске гранта РФФИ № 14-4501622 p_102_a.

\section{СІИСОК ЛИТЕРАТУРЫ}

1. Микрофизические параметры и элементный состав атмосферного аэрозоля в г. Барнауле в 2006-2008 гг. / В.Ю. Бортников, В.И. Букатый, И.В. Рябинин [и др.] // Известия Алтайского государственного университета. 2009. № 1. С. 106-110.

2. Способ мониторинга загрязнения атмосферного воздуха и система для его реализации / С.Н. Бугаев, В.Б. Жмур, В.Б. Лапшин [и др.] // Бюл. пат. тов. зн. М.: ФИПС, 2006. № 8. С. 1-6.
3. Дьяков Н.Н., Мальченко Ю.А., Боброва C.A. Фоновые характеристики гранулометрического состава аэрозолей г. Севастополя. Научно-исследовательские публикации. 2016. № 3(35). С. 5-13.

4. Кондратьев К.Я., Москаленко Н.И., Поздняков Д.В. Атмосферный аэрозоль. Л.: Гидрометеоиздат, 1983. $225 \mathrm{c}$.

5. Качество воздуха в крупнейших городах России за десять лет 1998-2007 гг / под ред. Э.Ю. Безуглой. СПб.: ГУ ГГО. Росгидромет, 2009. 133 с.

6. Ивлев Л.С. Химический состав и структура атмосферных аэрозолей. Л.: Изд-во Ленингр. ун-та, 1982. 368 с.

7. Ивлев Л.С., Довгалюк Ю.А. Физика атмосферных аэрозольных систем. СПб.: НИИХ СПбГУ, 1999. 194 с.

8. Экспериментальный автономный мониторинг размерных характеристик аэрозолей в различных районах Крыма / Ю.А. Мальченко, С.А. Боброва, В.В. Таранов [и др.] // Экологическая безопасность прибрежной и шельфовой $30 \mathrm{H}$ и комплексное использование ресурсов шельфа. Севастополь: ЭКОСИГидрофизика. 2013. Вып. 27. С. 38-42.

9. Чичаева М.A. Физико-химические характеристики аэрозолей приводного слоя атмосферы: автореф. дис. ... канд. физ.-мат. наук. М., 2010. 24 с.

10. Лазерный экспресс-метод диагностики водных и воздушных сред / В.В. Гончарук, А.О. Самсони-Тодоров, В.В. Таранов [и др.] // Электроника и связь. 2010. № 2. С. 161-166.

11. Мониторинг аэрозолей и состояния морской воды акватории Карадагского природного заповедника / В.В. Гончарук, А.О. Самсони-Тодоров, О.А. Савченко [и др.] // Химия и технология воды. 2015. 37. № 1. С. 10-22.

12. Система оперативного контроля качества воздуха в приморских городах и курортных зонах: загрязнение приводного слоя атмосферы морскими аэрозолями / В.В. Гончарук, В.Б. Лапшин, М.А. Чичаева [и др.] // Химия и технология воды. 2012. 34, № 2. С. 131-146. 
13. Директива N 2008/50/ЕС Европейского Парламента и Совета о качестве атмосферного воздуха и мерах его очистки. Европейский союз. Страсбург, 21 мая 2008 r.

14. Дополнение № 8 к ГН 2.1.6.133803 «Предельно допустимые концентрации (ПДК) загрязняющих веществ в атмосферном воздухе населенных мест». Гигиенические нормативы ГН 2.1.6.2604-10, Минздрав России, М., $2010 \mathrm{r}$.

15. Рекомендачии по качеству воздуха в Европе. Европейское региональное бюро ВОЗ. Изд. 2-е изд. М.: Весь мир, 2004. 34 c.

16. National Ambient Air Quality Standards for Particulate Matter; Final Rule. Federal Register. Vol. 71, No. 200, October 17, 2006 / Rules and Regulations ENVIRONMENTAL PROTECTION AGENCY.

17. $W H O$ Air quality guidelines for particulate matter, ozone, nitrogen dioxide and sulfur dioxide - Global update 2005 . Summary of risk assessment. (WHO/SDE/PHE/OEH/06.02) - WHO, 2006. 22 p.

18. Технический паспорт на прибор «Малоугловой измеритель дисперсности лазерный ИДЛ - 1». № $52.1440-2009$. Обнинск. 2009. 14 с.
19. Методика выполнения измерений «Малоугловой измеритель дисперсности лазерный ИДЛ-1», № 52.1440 2009. г. Обнинск. 2009. 35 с.

20. Перельман А.И. Геохимия ландшафта. М.: Высшая школа, 1975. 342 с.

21. Райст П. Аэрозоли. Введение в теорию. М.: Мир, 1987. 280 с.

22. Сыроешкин A.B., Чичаева M.A., Матвеева Н.С. Повторяемость взаимно однозначных зависимостей между концентрацией тяжелых металлов и дисперсностью морского аэрозоля (на примере двух экспедиционных исследований на Черном море) // Труды Государственного океанографического института им. Н.Н. Зубова. 2015. Вып. 216. С. 268-287.

23. Создание системы мониторинга техногенного загрязнения воздуха морских прибрежных городов и курортов / А.В. Сыроешкин, Т.В. Кондранин, В.Б. Лапшин [и др.] // Вестник РУдН. Серия: Медицина. 2009. № 4. С. 30-37.

24. Фукс Н.A. Механика аэрозолей. М.: Изд-во АН СССР, 1955. 351 c.

25. ISO 14644-1-99 Чистые помещения и связанные с ними контролируемые среды. Ч. 1: классификация чистоты воздуха. М.: Изд-во стандартов, 2003. 43 с.

\title{
USING THE METER SMALL-ANGLE DISPERSITY IN AUTOMATED SYSTEMS CONTINUOUS MONITORING PARTICLE SIZE DISTRIBUTION OF AEROSOLS
}

\author{
N.N. Dyakov ${ }^{1}$, Yu.A. Malchenko ${ }^{1}$, S.A. Bobrova ${ }^{1}$, A.I. Ryabinin ${ }^{1}$, A.E. Lipchenko ${ }^{1}$, \\ V.V. Taranov ${ }^{2}$
}

'Sevastopolskoe branch State Oceanographic Institute, Russian Federation, Sevastopol, St. Sovetskaya, 61

${ }^{2}$ Institute of Colloid Chemistry and Water Chemistry, NAS of Ukraine, Ukraine, Kiev-142, Av. Acad. Vernadsky, 42

We present the results of observations of the particle size distribution of aerosols on a stationary post in the city of Sevastopol in 2015-16 years. The basic patterns of aerosol distribution in individual size groups and their relationship with environmental parameters. The relevance of the proposed monitoring of the various indicators of aerosol was noted.

Keywords: aerosols, particle size distribution, diffraction of laser radiation, meteorological factors. 